\title{
A RELAÇÃo AFETIVA NA STTUAÇÃO DE APRENDIZAGEM: DIFERENTES SIGNIFICADOS E FORMAS DE ATUAÇÕES
}

\section{The affective relation in learning context: different meanings and performances}

\author{
Eloisa Quadros Fagali ${ }^{1}$
}

\section{Resumo}

Este artigo fornece elementos para reflexões sobre a conexão entre as relações afetivas e o processo cognitivo, nas situações de aprendizagem. Pesquisas de natureza participativa e qualitativa e projetos psicopedagógicos têm sido realizados em diferentes contextos do Brasil. Estes estudos focalizam as influências do contexto cultural, dos mitos e dos diferentes estilos dos aprendizes sobre os valores e significados que esses sujeitos atribuem às relações afetivas nas diferentes situações de aprendizagem. As experiências revelaram que ambas as relações afetivas positiva e negativa entre profissionais, aprendizes e objeto do conhecimento são responsáveis pelas mudanças no processo de aprendizagem e ensino. Este artigo focaliza a importância de se considerar as diferentes dimensões do afeto nas múltiplas formas do aprendiz atuar como professor, cuidador, junto aos colegas de trabalho e aos aprendizes nos diferentes ciclos de vida: infantil, juvenil e adulto.

Palavras-chave: Conexão; Afeição-cognição-aprendizagem; Tipologia; Contexto cultural; Mitos.

1 Doutora em Psicologia da Educação, Psicopedagogia, professora e supervisora em Arteterapia e Psicopedagogia (Instituto Sedes Sapientiae, PUCSP e Mackenzie). E-mail. nucleo_integracao@ibest.com.br 


\section{Abstract}

This article aims to provide elements for psychopedagogical reflections related to the connections between the affective relations and the cognitive process in the learning context. Qualitative, participating nature researches and the psychopedagogical projects have been made in different contexts in Brazil. These studies focuse on the influence on the cultural context, myths and different types of learners concerning the values and meanings that these learners attribute to the affective relations in the learning context. The experiments show that both the positive and negative affective relations among the professionals, learners and the object of knowledge are responsible for the changes in the learning and teaching processes. This paper focuses on how important it is to consider the different dimensions of affection on the multiple ways the learner/individual acts as a teacher or a carer next to his/ her workmates and the learners in different cycles of life: children, adolescent and adult.

Keywords: Connection, affection-cognition-learning; Typology; Cultural contexts; Myths.

\section{Introdução: Retrospectiva e problematização}

Nas reflexões e práticas que tenho desenvolvido desde os anos 70, como professora, psicopedagoga e terapeuta, considerando principalmente a formação de profissionais professores, orientadores e terapeutas nos cursos de pós-graduação e de formação continuada, algumas das questões básicas prioritárias nos estudos, projetos e pesquisas eram as seguintes:

- Quais as conexões entre o emocional e o cognitivo?

- Quais as influências dos aspectos afetivos no processo de aprendizagem dos indivíduos, nos diferentes ciclos de vida e dos grupos?

- O que o educador ou outros profissionais, com funções de cuidadores e orientadores e terapeutas significam sobre o valor das relações afetivas na dinâmica relacional de aprendizagem, em diferentes instâncias e atuações do aprendiz, no seu mundo existencial?

- Quais os diferentes valores e significados que os aprendizes alunos, clientes, e pais atribuem à afetividade, considerando a dinâmicá relacional interpessoal e intergrupal, nas situações de aprendizagem e de en$\sin 0$ ?

- Como o desenvolvimento de posturas e a ampliação de consciência das pessoas sobre os valores do afeto favorecem a dinâmica relacional afetiva na dinâmica interpessoal e grupal, gerando condições saudáveis para estas aprenderem, nas diferentes situações existenciais? 
Essas pesquisas baseiam-se nos dados colhidos dos projetos dos cursos de formação profissional de terceiro grau, em que desenvolvo as aulas e as supervisões, em diferentes regiões do Brasil, no período de 1979 a 2006 (São Paulo, Salvador, Fortaleza, São Luiz, Curitiba, Porto Alegre). São estudos que focalizam as interações entre as estratégias pedagógicas e os cuidados e posturas afetivas, considerando a dinâmica relacional entre aprendizes e orientadores. Essas práticas e reflexões resultaram no aprimoramento do planejamento de projetos e pesquisas psicopedagógicas, de natureza participativa (FREIRE, 1999) que culminaram na realização da minha tese de doutoramento (2001). Neste estudo focalizei a dinâmica relacional afetiva na escola pública, com destaque especial nas interações entre os aspectos afetivos e cognitivos, presentes em diferentes dinâmicas relacionais: as relações de parceria com pesquisadores, professores, coordenadores; os contatos com pais; as interações entre adolescentes, nas dinâmicas de sala de aula, tendo em vista as construções cognitivo-afetivas e a dialética entre as construções individuais e coletivas. Durante o desenvolvimento dessas pesquisas e de outras que continuam na atualidade (2006) aconteceram desdobramentos das primeiras questões já ressaltadas, revelando dados significativos em função das seguintes indagações:

- Em que medida os mitos culturais e a valorização e prática sociocultural sobre o desenvolvimento do afeto influenciam positiva ou negativamente nas construções do conhecimento e no desenvolvimento humano dos que aprendem e dos que ensinam e orientam?

- Quais as influências dos diferentes estilos cognitivo-afetivos e das variações de modalidades de aprendizagem sobre as percepções e atuações afetivas dos participantes no processo ensino-aprendizagem, tendo em vista as construções cognitiva-afetivas individuais e grupais?

As práticas e reflexões norteadas por estas questões apóiam-se numa abordagem epistemológica multirreferencial (Fagali, 2006a) em busca das articulações entre a teoria fenomenológica-ecossistêmica (Bronfenbrenne, 1996), a teoria analítica de C. Jung (Jung, 1997; Byington, 1995) a visão gestalt-terapêutica e gestalt-pedagógica (Polster, 1979; Burow, 1985; Hycner, 1997) e a abordagem sobre a complexidade do conhecimento e da ciência (MATURANA, 1997; MORIN, 1999).

As reflexões e práticas destacam como pano de fundo as diversidades e a natureza do processo de aprendizagem, focalizando os seguintes aspectos: a busca de diferenciações de significados sobre o conceito do afeto; as conexões entre afeto e cognição; a compreensão e criação das condições de ensino-aprendizagem que permitem ao aprendiz desenvolver-se de forma saudável e construir conhecimentos, tendo em vista as relações afetivas consigo 
mesmo e com o outro; as diversidades que se revelam nessas trocas simultâneas; as influências dos mitos e fatores culturais sobre a consciência e a prática de aprendizagem que envolve a relação afetiva, gerando mudanças ou estagnações dos indivíduos e grupos que aprendem, ensinam e constroem 0 conhecimento e o pensamento.

Não é objetivo do presente artigo esgotar todos os dados pesquisados e analisados, aspectos que tenho desenvolvido com diferentes enfoques em muitas publicações no decorrer destes anos (FAGALI, 2001, 2002, 2003, 2004, 2005, 2006).

A minha intenção, no presente artigo, é fazer um recorte das análises dos dados, levando em conta as respostas dos sujeitos que se colocavam como aprendizes adultos do curso de formação profissional de terceiro grau. Destaco nas reflexões e considerações finais os seguintes aspectos que considero de grande relevância:

- O espectro de significados sobre o afetivo, revelando as múltiplas formas de se lidar com a conexão entre afetividade e cognição na aprendizagem.

- As influências dos fatores psíquicos e culturais sobre as posturas de natureza afetiva e sobre os significados atribuídos à afetividade na aprendizagem: estilos cognitivo-afetivos; mitos da cultura e os tipos de formação profissional dos aprendizes, participantes da experiência.

- As mudanças dos mitos e das percepções sobre os significados e posturas em relação à afetividade, ocorridas durante o processo de aprendizagem mediado pelas intervenções que focalizavam a dinâmica afetiva entre os aprendizes, na relação consigo próprios e com os parceiros.

\section{Procedimentos}

As atividades desenvolvidas na situação de aprendizagem, para se dialogar com a afetividade, consistiam em propiciar encontros e trocas entre aprendizes, colocando em foco os significados e sentimentos em relação à afetividade na aprendizagem, considerando os diferentes ciclos de vida. Todas as aulas iniciavam-se com dinâmicas diversificadas em que se ampliavam as condições de escolhas de parceiros para trocas interpessoais mediadas por expressões de sentimentos e pensamentos entre os participantes. A título de ilustração, destaco uma das dinâmicas iniciais que consistiam em distribuir aos alunos, de forma aleatória, mensagens verbais ou visuais (figurativas) que expressavam diferentes questões sobre afetividade na relação do aprender, em qualquer experiência de vida. Essas mensagens consideram as emoções opostas associadas a prazeres e desprazeres. Cada aluno recebia uma mensa- 
gem, cuja repetição se encontrava nas mãos de outro colega. Realizava-se então a busca para o encontro daquele que recebeu a mensagem idêntica, criando no grupo um clima de descontração e de troca entre colegas em torno dessas informações. Os pares das mensagens comuns, ao se encontrarem, buscavam associações com o já vivido, levando em conta diferentes situações de aprendizagem e ciclos de vida. As expressões e reflexões sobre os pensamentos e sentimentos deveriam ser compartilhadas, tendo em vista as diferenças de percepções, no diálogo possível entre concordâncias e discordâncias.

Após as primeiras trocas, os pares encontravam-se com outras duplas que receberam mensagens diferentes, avaliando as complementações delas no grupo de quatro integrantes. Essas construções grupais progressivas, tendo em vista as análises sobre as identificações e diferenciações culminavam-se com a construção do grande grupo, a partir do diálogo aberto a todos, expondo com respeito os pensamentos, sentimentos e narrando experiências vividas de forma espontânea. Foram colocadas em foco as diferenciações e as oposições na relação afetiva, diferenciando as situações prazerosas e desprazerosas, paralizadoras e mobilizadoras, e expressando emoções associadas ao amor e ao ódio, à docilidade e à agressividade, à cooperação e à competição. As situações de aprendizagem sempre se referiam ao envolvimento com algum processo cognitivo, como a construção de um texto, 0 desenvolvimento e ampliação de conceitos de português, matemática, ou de ciências, o processo de alfabetização e outras experiências informais de aprendizagem nos contextos da escola, da família, do trabalho, e da vida em geral.

Estes resgates do vivido, com suas reflexões e variações de comunicações com o outro, por meio da expressão verbal e não verbal (desenhos, expressões cromáticas, contos) eram feito em um clima ameno e descontraído, mobilizado por uma música de fundo que propiciava a cinergia e a formação de um ambiente empático e espontâneo que favorecia a troca e a ampliação dos saberes a respeito do que se entendia sobre o afetivo e sobre suas conexões com a aprendizagem e o processo cognitivo. Em outras palavras, essa dinâmica em torno do pensamento e sentimento compartilhado, como muitas outras atividades criadas e desenvolvidas, mobilizava o respeito pelos diferentes mitos e valores sobre o afetivo, bem como a ampliação dos conceitos, e o desenvolvimento da consciência e das posturas que envolviam afetividade.

Este projeto acoplado à pesquisa tinha a duração de 4 meses, com duas aulas semanais (40 minutos hora/aula).

\section{Discussões e elaborações teóricas em torno da análise dos dados}

As respostas dos sujeitos, no início, começo e finalização do processo foram analisadas qualitativamente e agrupados em diferentes categorias, 
conforme o revelado na análise dos conteúdos. Em busca de recortes destas categorias que se associam as intenções do presente artigo, destaco a seguir algumas delas nos itens abaixo, para ampliar nossas discussões:

- A importância das experiên cias de contato na aprendizagem e as implicações da relação afetiva conectadas às criações cognitivas:

As respostas avaliativas dos sujeitos aprendizes, ao se referirem às experiências vividas por eles nos projetos, ressaltavam com freqüência significativa o quanto foram importantes e positivas as dinâmicas interativas desenvolvidas por favorecerem o contato de cada um deles consigo próprio e com o outro. Esses contatos, permeados pelos diálogos sobre o que era diferente e idêntico em relação às experiências relatadas e as percepções, possibilitavam uma maior aceitação e compreensão dos integrantes sobre as dificuldades de aprendizagem e ampliavam a consciência de todos os aprendizes em relação às suas capacidades para se flexibilizarem frente ao diferente, ao novo e às resistências. Segundo as avaliações dos participantes, as experiências de contato possibilitavam a criação de condições de aprendizagem que favoreciam a assimilação de novos conhecimentos e do desenvolvimento de recursos para se buscar soluções frente às situações problemas presentes na aprendizagem.

Articulando estes resultados com as reflexões teónicas, destaco a visão da Gestalt-terapia em relação a este fenômeno tão enfatizado pelos sujeitos da pesquisa como fator positivo e mobilizador. o contato. Nesta abordagem com enfoque fenomenológico, o contato constitui-se como o relacionamento dinâmico que ocorre somente nas fronteiras de duas figuras: eu-outro, eu-grupo, eu-objeto, eu-meio. A experiência de contato se processa nessa fronteira. Segundo Polster (1979: 109: p.99)

a seletividade de contato determinado pela fronteira do eu do indivíduo orientará o seu estilo de vida, incluindo a sua escolha de amigos, trabalho, geografia, fantasia, fazer amor, e todas as outras experiências que são psicologicamente relevantes para a sua existência. $\mathrm{O}$ modo pelo qual uma pessoa bloqueia ou permite a consciência e a ação na fronteira de contato é o seu modo de manter o senso dos seus limites. Isto tem uma preponderância em sua vida que ultrapassa quaisquer preocupações com o prazer, ou com o futuro, ou com aspectos práticos daquilo que pode ou não ser bom para ele...

. A relação afetiva, portanto, está implícita nas diferentes formas de contato que requerem a dinâmica interacional eu-outro, eu-meio, mobilizada por uma rede de interações de forças, em que entram em jogo as diferenciações e os movimentos de aproximação e afastamentos das pessoas, carregadas por diferentes emoções, percepções e fantasias. Este processo ocorre em todas as condições de aprendizagem, inclusive naquelas que envolvem a construção do conhecimento formal ou informal e estava presente em toda a dinâmica relacional desenvolvida na pesquisa, sendo conscientizada e ressignifica- 
A relação afetiva na situação de aprendizagem: diferentes significados e formas de atuações

da nas trocas com os aprendizes quando percebiam esta importância do contato ainda de forma intuitiva e empírica. $\mathrm{O}$ que se observava na dinâmica era intensificação deste contato, colocando-o em pauta, ao considerar as dimensões afetivas deles, em conexão com a cognição.

- As reduções e ampliações de significados sobre o afetivo:

Dos dados analisados, 85\% das respostas dos sujeitos mantinham uma concepção de que afetividade estava sempre associada a fatores positivos que geravam a aproximação das pessoas consigo próprio, com os outros e com o objeto do conhecimento. As análises dos conceitos expressos pelos aprendizes sobre afetividade revelavam o quanto as definições sobre este fenômeno manifestavam-se muito linear e reducionista, associando a dinâmica afetiva sempre a uma condição de aceitação e de prazer. Os que traziam uma visão menos reducionista eram pouco freqüentes, mas se revelavam mais flexíveis na relação com os diferentes afetos agradáveis e desagradáveis que emergiam na dinâmica. A partir destas constatações percebidas e discutidas no grupo, buscou-se uma ampliação do conceito de relação afetiva por meio de diferentes discussões e dinâmicas em que se levava em conta a alteridade, isto é, o jogo entre as oposições e as diferenças, a dialógica entre o afastar-se e aproximar-se. A proposta era ampliar a visão da afetividade tendo em vista a dinâmica dialógica entre as condições prazerosas e as desprazerosas.

Esses dados nos remetem ao que E. Morin (1999a, b) nos fala sobre a complexidade do homem e do pensamento, apontando para a necessidade de se enfatizar a diversidade e a inclusão bem como o diálogo entre os opostos e o paradoxal. Ressalta a necessidade da nossa cultura que possibilite a dialógica entre satisfação-insatisfação, prazer-desprazer, ganhos-perdas, concordâncias-discordâncias, ampliando as condições de inclusão e a aceitação das oposições que possibilitam o desenvolvimento de posturas mais flexíveis e com abertura emocional para incluir o novo e o diferente. São condições de aprendizagem que geram descobertas em direção a uma nova ordem regida por uma nova forma de pensar e de sentir gerando integrações do homem e da cultura e o respeito às diferenças. Nessas situações que envolvem este diálogo, a afetividade se constitui como uma disposição emocional que possibilita o movimento complementar e contínuo entre o aproximar-se e o distanciar-se dos diferentes ângulos do eu, do outro, do sociocultural e do objeto de conhecimento. A manifestação afetiva nesse sentido requer movimento de cooperação sem excluir a competição e a busca da identidade apesar das diferenças e discordâncias. Como já foi assinalado, a abordagem da Gestalt-terapia supõe essa dinâmica entre o afastar-se e o aproximar-se, e o movimento dialógico entre os pólos opostos. Se recorrermos às idéias psicanalíticas, deparamos também com esta visão dinâmica entre as emoções: amor e ódio, frustrações e prazeres, falta e preenchimento. Winicott (1975), numa visão psicanalítica, 
leva em consideração essa dinâmica entre os opostos. De um lado o autor ressalta a importância da função materna como o "colo" que dá o suporte afetivo possibilitando ao bebê o acolhimento, e aceitação. Por outro lado considera que essa condição saudável carregada de prazeres que levam ao desenvolvimento da autoconfiança da pessoa, desde a sua origem, necessita ser complementada por outra experiência que requer o diálogo com as frustrações e diferenciações que favorecem o desenvolvimento da autonomia e auto-aceitação da pessoa, de forma que esta se autorize como construtora de si próprio e do conhecimento. Os estudos analíticos de Jung (1987) e Byington (1995), ao levar em conta o desenvolvimento da psique, considerando a dinâmica do inconsciente e consciente individual e coletivo, refere-se ao processo de individuação da psique humana em que ocorre o diálogo entre os opostos, tendo em vista diferentes dimensões do homem e a dinâmica entre os processos individuais e coletivos e as forças conscientes e inconscientes.

Esta dinâmica entre os opostos ocorre em todas as condições de aprendizagem, inclusive naquelas que envolvem a construção do conhecimento formal e informal, no entanto os dados colhidos das pesquisas revelam a tendência reducionista do homem, associando a relação afetiva à emoção associada ao prazer, o que nos leva a supor a influência dos mitos culturais, dos paradigmas sociais que se manifestam mostrando este movimento de separação e de exclusão diante das diferenças e oposições (MORIN, 1999,a,b).

Nesse sentido, a aprendizagem que possibilita o autoconhecimento e o conhecimento do outro e do objeto do saber, levando em conta o processo de individuação, o jogo entre as emoções opostas e diferentes, ampliam as condições do homem aprendiz para que este possa flexibilizar-se afetivamente, diante das construções cognitivas relacionadas a si próprio, ao outro e ao conhecimento em geral, seja este homem criança, adolescente ou adulto, em qualquer condição de vida, de desenvolvimento pessoal e de funções.

- Diferentes estilos individuais que influenciam na forma de conceber e de lidar com o afeto:

$\mathrm{Na}$ análise dos dados das pesquisas realizadas constatam-se a influência dos diferentes tipos de pessoas sobre as suas formas de conceituar e de lidar com a afetividade. Os dados demonstraram que os aprendizes que tendiam a valorizar mais o afetivo em qualquer circunstância de aprendizagem, favorecendo com suas posturas a troca interpessoal e intrapessoal revelavamse com características muito semelhantes ao que C. Jung denomina de tipo sentimento com atitudes introvertidas (voltar para si próprio) e extrovertidas (contato com o outro). Estes tipos mostram-se com disposições de personalidades voltadas para o diálogo com as emoções, para o envolvimento com as relações vinculares. São dotados de empatia e capacidade de se perceber e de se colocar no lugar do outro, o que facilita a troca interpessoal e intrapessoal. 
Nos estudos psicopedagógicos que tenho me aprofundado sobre estes tipos e que denomino de estilos cognitivo-afetivos, essas características associadas à função sentimento de Jung associa-se ao que H. Gardner denomina de inteligência interpessoal e intrapessoal. Estes aprendizes que traziam esses traços envolviam-se e contribuíam com muita habilidade paras trocas interpessoais desenvolvidas no projeto, mostrando-se mais empáticos e com maiores capacidades de articulações afetivas e de auto-análise, mesmo diante das diferenças e contradições de sentimentos e pensamentos que ocorriam na relação entre os pares. Jung enfatiza nessa dinâmica em que se destaca a função sentimento, assim como nas outras funções, a dialética entre inconsciente e consciente, enquanto H. Gardner destaca apenas os fatores cognitivos associados a esta inteligência como as habilidades sociais que influenciam na forma eficiente de lidar com a comunicação eu-outro, na construção grupal, favorecendo as relações afetivas positivas e empáticas que geram a produtividade humana coletiva e individual, nos diferentes contextos de aprendizagem.

Considerando a visão da Gestalt-terapia, esta traz a questão das diferentes formas de atuar e sentir ao se referir sobre o conceito de fronteiras do contato. Embora a fronteira do eu não seja fixada de uma forma rígida, mesmo nas pessoas mais inflexíveis, os indivíduos mostram grande variabilidade na expansividade ou contractibilidade da sua fronteira do eu. Algumas pessoas parecem realizar grandes modificações na sua fronteira do eu durante as suas vidas e estamos inclinados a pensar que naquelas que mostram as maiores modificações são as que mais cresceram. Isto pode ocorrer desde o acontecimento fortuito, sobre o qual elas têm pouco controle, mas ao qual parecem responder enérgica e habilmente, até aquelas mudanças que os seus próprios esforços produziram.

- O espectro dos níveis de afeto relacionados aos mitos culturais e às múltiplas formas de aprender e de conhecer:

Os dados demonstraram como as modalidades de aprendizagem e os mitos culturais predominantes na cultura do cuidador, do aprendiz ou da Instituição influenciam na forma de perceber e de lidar com a relação afetiva nas diferentes situações de aprendizagem. Na análise dos dados colhidos, no início do projeto, percebia-se uma maior freqüência de respostas que consideravam a afetividade como um elemento secundário a ser cuidado, dando maior ênfase às construções cognitivas e mentais. Destacavam medos e conflitos em relação às dinâmicas que focalizam a afetividade em sala de aula, como se este fator não fosse o mais importante no espaço pedagógico. Advertiam sobre o perigo desta preocupação sobre o afetivo dominar ou excluir a construção do conhecimento e do pensamento e de não ter condições de controle quando este emerge. As respostas destes sujeitos tendiam a transferir os objetivos e estratégias pedagógicas que focalizam os aspectos afetivos para outros cuida- 
dores e instâncias de aprendizagem associadas às funções exclusivas de psicólogos e de trabalhos clínicos. Estas respostas eram mais freqüentes entre os aprendizes com formação pedagógica ou formação de professores especialistas de segundo e terceiro graus.

Para buscar uma maior reflexão sobre estas nuances de sentidos em torno do afeto, gostaria de ressaltar a visão holística de Ken Wilber (1977) que nos fala sobre o "espectro da consciência", metáfora inspirada na radiação eletromagnética, que consiste num espectro de energia com vários comprimentos de ondas. Segundo Wilbwe, esses diferentes níveis de consciência humana, nas dimensões físicas, psíquicas, existenciais, mentais e espirituais sugerem diferentes demandas e as diversidades de intervenções individuais e coletivas do homem e das culturas, para ampliar a consciência do homem, em busca da integração desses diferentes níveis. Essa nuance de significado e dimensões se associam às múltiplas modalidades associadas ao ensino e a aprendizagem. Por que não ampliar as condições de aprender em busca deste deslocar-se entre diferentes níveis de afeto conectando emoções com o conhecimento e o desenvolvimento de conceitos? Maturana (1997) ressalta a importância de se considerar a condição do emocional no ato do pensar reforçando que todo pensamento é sustentado por uma crença e um "emocionar". Fala-nos sobre o paradigma predominante na nossa cultura ocidental em que se dissocia o subjetivo do objetivo, o afeto da cognição, o emocionar do ato de pensar. Em muitos estudos e publicações que tenho desenvolvido, ressalto as contribuições das abordagens analíticas sobre as reflexões de Byngton, apoiadas nas contribuições de Jung, quando ele se refere à dinâmica inconsciente e consciente coletiva da escola e dos contextos educacionais. $\mathrm{O}$ referido autor ressalta como a dinâmica relacional patriarcal mais presente na cultura ocidental enfatiza o poder do pensamento e da construção do conhecimento apoiado no pensamento lógico, nas produções estruturantes, dissociado das dimensões afetivas e emocionais. Essas culturas patriarcais reprimem tudo que se refere às dinâmicas relacionais próprios do sistema matriarcal que valorizam o processo empático, a construção do afeto, o desenvolvimento de posturas mais comprometidos com a subjetividade, a ética e a valorização de uma inteligência associada às habilidades sociais e empáticas que requerem trocas de sentimentos e o autoconhecimento. Na cultura da escola ocidental, esses processos associados à dinâmica matriarcal deveriam ser mais enfatizados e desenvolvidos conscientemente no nível individual e coletivo, de forma a integrar com a dinâmica patriarcal. Tendo em vista essas reflexões, as pesquisas revelaram mitos sobre o aprender que expressam essa dissociação e desconexão entre 0 pensamento e 0 afeto, entre a relação de aprendizagem focada no conhecimento e as condições de aprendizagem que valorizam as situações emocionais humanas. 
Na evolução dos trabalhos em que se ampliavam as dinâmicas relacionais afetivas integradas ao desenvolvimento dos conceitos, percebeu-se, por meio das avaliações e atitudes dos participantes, transformações dos mitos excessivamente patriarcais e conseqüentes mudanças em relação ao conceito de aprender e de conhecer, com aberturas para considerar o espectro de diferentes sentidos em torno do afetivo, da consciência humana e da aprendizagem.

\section{Considerações finais}

As análises ressaltadas no presente artigo nos colocam frente aos grandes desafios de todos nós, educadores contemporâneos, atuantes como professores, orientadores, coordenadores, psicopedagogos, cuidadores e terapeutas, nos diferentes contextos de aprendizagem. Este desafio mobiliza-nos para olhar e cuidar da aprendizagem levando em conta uma compreensão psico-sóciopedagógica que incluem as conexões entre as dimensões do afeto e da cognição, numa visão ampliada e complexa do processo do aprender e do homem, seja este um aprendiz criança, adolescente e adulto que atuam, com suas diferentes funções, em qualquer experiência e contexto de aprendizagem.

Em conclusão, há de se considerar, a partir das reflexões e práticas destes projetos e pesquisas, com suportes teóricos de natureza psico-sóciopedagógica, os seguintes aspectos associados à concepção da relação afetiva e suas articulações com a cognição:

- A relação afetiva implica na dinâmica relacional interativa eu-outro e na dialética entre a construção individual e coletiva.

- A relação afetiva consiste em movimento dialético entre emoções diferentes e opostas: aceitação e rejeição, amor e ódio, envolvimento e indiferença, prazeres e frustrações, concordâncias e discordâncias.

- A afetividade, segundo uma concepção mais ampla e menos reducionista, requer um aprofundamento focalizando o diálogo interno do aprendiz consigo próprio, na busca do seu autoconhecimento, levando em conta as condições de aceitação e rejeição, de exclusão e inclusão das diferentes faces do homem que é por natureza complexo e necessita ir em busca da possível integração, para além da percepção e do conhecimento fragmentado.

- Na dinâmica interpessoal presente no processo de aprendizagem há de se considerar as conexões entre o autoconhecimento, as trocas interativas interpessoais e o diálogo com o objeto do conhecimento, considerando o diálogo afetivo com o diferente e o oposto.

- O olhar para a aprendizagem e a sua prática, deve considerar as influências das forças afetivas individuais e culturais, conscientes e inconsci- 
entes, para ampliar a visão de uma aprendizagem que requer as integrações entre subjetividade e objetividade, e a postura e mediações pedagógicas e terapêuticas, com uma visão ecossistêmica que considera valores, paradigmas e mitos que influenciam na aprendizagem individual e grupal, e que caracterizam diferentes dinâmicas de natureza afetiva e cognitiva, nas relações de ajuda.

- Nas conexões entre afeto e cognição, deve-se levar em conta os diferentes estilos cognitivo-afetivos associados aos tipos de personalidade e às diversidades de modalidades de aprendizagem, tendo em vista o espectro de significados e de consciência do homem e as diversidades de atuações, nas relações de ajuda.

- A aprendizagem que envolve a afetividade requer um movimento de olhar de quem ensina e orienta articulando o autoconhecimento ao conhecimento do outro. Nesse sentido, a proposta de psico-sócio-pedagogia contemporânea é criar espaços para refletir e mobilizar os cuidadores no sentido de ampliar as condições de aprendizagem com o objetivo de desenvolver exercícios e fazer reflexões em relação às conexões entre afeto e cognição, fatores culturais e individuais, e as trocas entre as diferenças e jogos de oposições que se complementam. A prática e reflexão psico-sócio-pedagógica necessita da ampliação da visão de aprendizagem, tendo em vista uma percepção e pensamento ecossistêmico que buscam as conexões entre a visão local, particular (história e demanda dos sujeitos) e a visão global (história coletiva e forças culturais), levando em conta outras conexões entre afeto e cognição, pensamento e emoção, ampliando o sentido da terapêutica na prática pedagógica..

Em conclusão, gostaria de ressaltar o sentido do terapêutico, quando se fala da intersecção entre o afeto e a cognição. Apesar de contarmos, atualmente, com estudos e práticas consistentes que fornecem significativas colaborações para a identidade da psicopedagogia, focalizando o olhar e a postura terapêutica na situação de aprendizagem, ainda deparamos com certas tendências teórico-práticas que muitas vezes diluem ou reduzem o sentido do terapêutico devido à falta desta conexão entre o afeto e a cognição e a ênfase nas reduções conceituais em relação ao afeto na aprendizagem . Há tendências que ...

de um lado resultam em generalizações excessivas dos conceitos em torno da relação terapêutica a ponto de "pulverizar" o próprio sentido de intervenção nas relações de ajuda, perdendo de vista as diferenças de atuações que se complementam e que exigem formações específicas para o trabalho terapêutico, numa abordagem transdisciplinar e interdisciplinar. Por outro lado, há outros pensamentos que tendem a reduzir o sentido do terapêutico psicopedagógico, considerando-o apenas como uma "reeducação" sofisticada que enfatiza o desenvolvimento das habilidades cognitivas e focaliza como indicador essencial o trato com os distúrbios, deficiências e patologias. 
Essa última tendência afasta-se da polêmica, com uma posição simplista sobre as diferenciações entre os profissionais: aqueles que cuidam do emocional (psicoterapeutas psicólogos) e outros que lidam com o cognitivo (psicopedagogos). Essas posições podem ser consideradas como a expressão de mitos e paradigmas que reforçam uma visão fragmentada do conhecimento e do homem, separando os aspectos cognitivos dos emocionais. São reflexões que tendem a evitar os pontos conflituosos diante das inevitáveis nuances da relação terapêutica, e das diferentes dimensões do homem e do conhecimento, negando as relações indissociáveis entre cognição, pensamento, emoção e imaginação. Essas buscas de diferenciações de trabalhos cindem a natureza humana e o conhecimento, e geram fragmentações do aprendiz e da aprendizagem, ignorando a subjetividade na construção do conhecimento. Enfrentar essa polêmica sobre os diferentes sentidos do terapêutico é mais saudável se considerarmos concepções mais complexas do homem e do saber, mantendo o diálogo com a complexidade dos fenômenos e a inclusão das diferenças, mesmo que surjam ambigüidades e incertezas. Nessa perspectiva, é necessário considerar os pontos de intersecção, as identidades e diferenças entre as atuações terapêuticas, numa visão e postura interdisciplinar e transdisciplinar. É fundamental que se considere as nuances sutis de atuações terapêuticas, nessa dialógica entre o afeto e a cognição, subjetividade e objetividade, emoção, pensamento e imaginação, para maior compreensão sobre as diferentes formas de intervenções terapêuticas, no processo do aprender, em diferentes contextos (FAGAL, 2006).

Agradecimentos pela colaboração da equipe interdisciplinar do Núcleo Psicopedagógico Integração e da Ong InterAção que fundei a partir dos anos 80 e 90, com agradecimentos às contribuições especiais nas pesquisas dos profissionais psicopedagogos: Anita Abbed Zuppo, Márcia Benevitz, Marco Menitz, Liliane Henriques, Gloria Taoki e Cleide Catelan.

\section{Referências}

BRONFENBRENNER, I. A ecologia do desenvolvimento humano: experimentos naturais e planejados. Porto Alegre: Artes Médicas, 1996.

BY INGTON, C. A pedagogia simbólica. Rio Janeiro, RJ: Rosa dos Ventos, 1995.

BUROW, A. O Gestaltpedagogia um caminho para a escola e a educação. São Paulo, SP: Summus, 1981.

FAGALI, E. Q. Múltiplas formas de aprender: novos paradigmas da pósmodernidade. São Paulo, SP: Unidas-Integração, 2001a. 
. A dinâmica relacional, a subjetividade, o múltiplo e o transitar na aprendizagem de adolescentes de quinta série. Tese (Doutorado) - PUC, São Paulo, 2001b.

. Diferentes instâncias do aprender e influências do contexto cultural: uma abordagem fenomenológica ecossistêmica. RevistaConstrução Psicopedagógica. São Paulo, v. 17, n.9, 2004a.

. O aprender na transição mediado pelo pensamento imaginário-metafórico ecossistêmico. In Masini, E.(org), Condições para aprender. São Paulo, SP: Vetor, 2004b.

. Criando espaços para novas contribuições psiopedagógicas: entre contexto clínico e institucional: abordagem multireferencial fenomenológica ecossistêmica. In MASINI, E. Uma jornada de reflexão sobre a prática em psicopedagogia. São Paulo, SP: Vetor, 2005a.

. Encontros entre arteterapia e psicopedagogia: a relação dialógica terapeuta e cliente, educador e aprendiz In Ciomai (org), Percursos em arteterapia. São Paulo,SP: Summus, 2005s.

. Múltiplos sentidos doterapêutico: intervenções psicopedagógicas em diferentes contextos de aprendizagem. Psicopedagogia: Revista da Associação Brasileira de Psicopedagogia, 2006. (no prelo).

FREIRE, P. Criando o método de pesquisa participativa. In: BRANDÃO (Org.). Pesquisa participante. São Paulo, SP: Brasiliense, 1999.

HYCNER, R. Jacobs. Relação e cura em gestalt-terapia. São Paulo, SP: Summus 1997.

JUNG, C. 0 homem e seus símbolos . Rio de Janeiro, RJ: Nova Fronteira, 1985.

MATURANA, E. A ontologia da realidade. Belo Honizonte: UFMG, 1997.

MORIN, E. Ciência com consciência. São Paulo, SP: Bertrand Brasil, 1996.

. Ométodo 3: o conhecimento do conhecimento. Porto Alegre: Sulinas, 1999.

POLSTER, I. E. M. Gestaltterapia integrada. Rio de Janeiro, RJ: Interlivro 1979.

WILBER, K. Espectro da consciência. São Paulo, SP: Cultrix, 1997.

WINICOTT, D.T. O brincar e a realidade. São Paulo, SP: Imago, 1975. 